\title{
La ciudad de Valencia como espacio percibido por los estudiantes universitarios. Aportaciones desde el análisis propuesto por la geografía de la percepción \\ Valencia City as perceived space for college students. Contributions from an analysis proposed by the geography of perception
}

\author{
Francisco José Morales Yago ${ }^{1}$
}

\section{INTRODUCCIÓN}

Hace más de medio siglo, concretamente en la década de los años 60, apareció una nueva tendencia entre los geógrafos anglosajones, la denominada «geografía humanista». Esta propuesta supuso la difusión de métodos innovadores como la observación participativa, la cual promovía el planteamiento de las relaciones de los seres humanos con el mundo que les rodeaba y su comportamiento. Este enfoque interpretó que la utilización del espacio no sólo está condicionada por factores económicos y sociales. Así nació la geografía del comportamiento y de la percepción, influenciada en su planteamiento epistemológico por otras disciplinas del conocimiento como serían la psicología o la sociología. Ello condujo a la apertura del pensamiento existencialista y fenomenológico, y por tanto a la consideración de las «imágenes mentales» que indicaran entre otros los caminos que utilizamos para desplazarnos, los lugares que frecuentamos y los sentimientos de identificación o rechazo con el territorio. Destacamos que en esta corriente de pensamiento geográfico tuvieron gran influencia los planteamientos de la Escuela de Chicago sobre urbanismo, seña-

*Departamento de Geografía, Facultad de Geografía e Historia de la UNED (fjmorales@geo. uned.es). Miembro del Grupo de investigación: «Cultur-pais» 
lando a Kevin Lynch en su obra The image of City del año 1960. Se llevó a cabo una importante crítica de los planteamientos positivistas, demostrando falta de rigor en los modelos teóricos de la geografía analítica. De hecho, Wolpet mencionó el comportamiento humano como un hecho individual, nunca colectivo, apareciendo una corriente de pensamiento dedicada hacia la problemática social y hacia temáticas relacionadas con la ordenación y planificación territorial, desde un análisis preferente por los temas relacionados con el espacio vivido.

El planteamiento teórico de esa tendencia se basó en admitir que los seres humanos acumulan una serie de imágenes en su mente lo que puede dar lugar a la realización de mapas «mentales» individuales y también colectivos; lo que significaría abrir una nueva «cartografía» entre el mundo real y la conducta humana. Desde los años 80 se puede afirmar que el objeto de estudio de esta geografía de la percepción se ha centrado mucho en el análisis de lo subjetivo, siendo la encuesta, el mapa mental, la entrevista y el análisis complementarios de otras fuentes de datos las principales técnicas utilizadas.

Estébanez (1979) señaló que los estudios de la percepción, por su complejidad eran claramente interdisciplinarios ya que medir las imágenes, en este caso de la ciudad, podía caer en el peligro de manipulaciones según la ideología e intereses del grupo o persona que realizase el trabajo.

Reques y Boira (1992) aportaron en su trabajo la falta de criterios generales a la hora de aplicar esta metodología al conjunto nacional, incidiendo en la individualidad de los trabajos según el espacio estudiado y proponiendo una mayor concreción en la aplicación de métodos y técnicas que ayuden a enriquecer el estudio del espacio subjetivo de las ciudades, teniendo presente que todo estudio del espacio geográfico debe tener como elemento central al hombre y su relación con el medio que le rodea (Gutiérrez y Peña, 1996).

En diferentes trabajos de Boira y Maiques (1992-2005) se desarrolló un planteamiento que ha permitido considerar que la geografía de la percepción es un instrumento de planeamiento urbano y ordenación territorial. Se señalaba así la falta de atención, por parte de los técnicos que diseñan las ciudades, a la participación activa de los ciudadanos y colectivos; de ahí la falta de reflexión y análisis sobre el espacio subjetivo, tanto en su aspecto didáctico (conocer y enseñar la ciudad), como en el planeamiento urbano y territorial. En el campo de la Geografía de la Percepción es importante destacar los trabajos de De Castro Aguirre (1995-2005) en donde se realiza el análisis urbano desde la perspectiva del comportamiento y se proponen dos instrumentos de trabajo: la construcción de mapas y atlas cognitivos, resaltando que la Geografía Comportamental es una ciencia explicativa que pone al descubierto ciertos mecanismos de conducta que sin duda servirán a los intereses de la ordenación del territorio, En el 
primero se trabaja el desplazamiento ahuyentando el riesgo de perdernos en la jungla urbana y en el segundo la información sobre los lugares geográficos, más allá de los entornos habituales de desplazamiento (Boira, 1998).

Otros trabajos de Reques Velasco (2006) valoran positivamente la geografía de la percepción como herramienta que permite conocer la imagen subjetiva del espacio y la interacción con el mismo. En el trabajo de Somoza Medina (2006) sobre la ciudad de Orense destaca cómo es imprescindible para la explicación objetiva del espacio tener en cuenta «ciertas características del comportamiento ciudadano» (pág. 309) presentando una serie de mapas mentales relacionados con el barrio de «Las Lagunas» de esta ciudad del interior gallego.

Finalmente destacamos los trabajos de Vara Muñoz (2008-2010), que centra su trabajo en la realización de mapas cognitivos o mentales, encuestas o entrevistas y análisis de textos como medio de conocimiento de las percepciones espaciales. A través de esta bibliografía y la de otros autores estimamos oportuno contar, para nuestro estudio de la ciudad de Valencia, con un colectivo de estudiantes universitarios cuyas aportaciones podrán llevarnos a conclusiones significativas sobre la imagen mental de los espacios emocionales de esta urbe del litoral mediterráneo español.

\section{Metodología de trabajo}

La metodología empleada se basa en el enfoque de varios autores reseñados en el apartado anterior. En primer lugar abordaremos el enfoque descriptivo de Lynch (1960), que centró su objetivo en el análisis de la calidad visual de tres ciudades estadounidenses: Jersey, Boston y Los Ángeles. Lynch consideraba que las personas estructuran y recuerdan el paisaje urbano a través de una selección de determinados componentes. Estos componentes son: hitos, distritos, sendas, nodos y bordes. La combinación de estos elementos en el paisaje urbano determina la mayor o menor legilibilidad de la ciudad y su mayor o menor imaginabilidad, que es la propiedad del paisaje urbano de evocar imágenes más o menos nítidas en la mayoría de los observadores. Por lo tanto, la mejor representación de una ciudad permite que el observador la recuerde y evoque con facilidad y pueda reproducir en la mente imágenes muy plásticas de la misma.

Basado en el trabajo de campo y en la encuestas sobre esquemas gráficos y descripciones verbales de la ciudad, K. Lych señaló que la imagen mental del paisaje urbano estaba formada por cinco elementos estructurales:

- Sendas: Son las vías o caminos seguidas por cualquier individuo normalmente, ocasionalmente, o potencialmente, en su deambular por la ciu- 
dad. Son las calles, canales, vías de ferrocarril. Para muchas personas son los elementos principales de la ciudad.

- Nodos: Son puntos estratégicos de la ciudad: lugares de confluencia de circulación o de ruptura de transporte, como plazas, puertos, aeropuertos, estaciones de ferrocarril o de autobuses. A menudo estos lugares concentran actividades centrales de la ciudad y encierran valores simbólicos y representativos de la ciudad o barrio.

- Barrios: Son áreas urbanas que los ciudadanos perciben como espacios bien diferenciados de otros por razones de tipo administrativo o por las características de su morfología, significado funcional y composición de su población.

- Hitos: Son elementos del paisaje urbano que la mayoría de sus habitantes utilizan como puntos de referencia y guía: la torre de una iglesia, el ayuntamiento, un monumento.

- Bordes: Son los elementos que separan espacios diferenciados morfológica o socialmente. Pueden ser límites materiales, como líneas de ferrocarril, murallas, ríos, frentes de costa, usos distintos del suelo, o límites percibidos, como áreas residenciales de determinadas características sociales o zonas de miedo.

Los autores Pocock y Hudson (1978) simplificaron la clasificación de Lynch, reduciéndola a tres tipos de elementos: aspectos puntuales, lineales y áreas.

A parte del enfoque visual, también habrá que considerar los aspectos valorativos y preferenciales (Zárate, 2006), que hacen referencia a la dimensión apreciativa de la imagen con vistas al comportamiento y a la toma de deci-

\section{Cuadro 1}

\section{ASPECTOS ESTRUCTURALES DE LA IMAGEN URBANA}

\begin{tabular}{ll|ll}
\hline & A. Edificios: Eclesiásticos & & \\
& Históricos & & \\
& Cívicos & Aspectos & \multicolumn{1}{c}{ C. Lineales: Calles } \\
& Educativos \\
Aspectos & Sociales & Sendas \\
puntuales & Comercio & & \\
& Negocios & & \\
& Transporte & & D. Áreas: Nodos \\
& B. Hitos: Viaductos & Distritos \\
& Puentes & Áreas & Espacios Abiertos \\
& Movimientos & & \\
\hline
\end{tabular}

Fuente: elaboración a partir de los trabajos de D. Pocock, y R. Hudson (1978). 
sión. Para investigar la componente apreciativa de la imagen se utilizan técnicas variadas, que van desde el método diferencial semántico, o el empleo de técnicas estadísticas de análisis factorial, a técnicas muy sencillas, pero prácticas, que aplican una escala ordinal a los lugares o elementos seleccionados por los individuos, en una puntuación inversa al orden de estimabilidad para elaborar mapas preferenciales. A un grupo de alumnos universitarios del Grado de Magisterio de la Universidad Católica de Valencia se solicitó dibujaran un plano de la ciudad, señalando los barrios y el mayor número de elementos visibles que recuerden, que pudieran servir como referencias de orientación para cualquier individuo que no conociera la ciudad y fuera a visitarla por primera vez. Siguiendo los modelos de encuesta de percepción urbana elaborados por Consuelo del Canto y Otros (1988) así como el presentado por Zárate (1993), hemos diseñado un cuestionario adaptado a la ciudad (ver anexo). Los objetivos primordiales fueron el análisis de la imagen mental del conjunto urbano y de manera especial el «centro». Los resultados de esta encuesta practicada a 300 alumnos universitarios resultaron muy significativos.

A partir de estos resultados se efectuó un análisis de percepción destacando, entre otros, aspectos tan relevantes como los elementos estructurales de la ciudad, lo que se echaría en falta en caso de tener que abandonar la misma, los lugares que se mostrarían en caso de tener que enseñar a la ciudad a potenciales visitantes, la utilización del centro urbano en referencia al barrio de Ciutat Vella (Gaja, 2009), la movilidad y el transporte y el sentido emocional de los lugares o espacios que componen el conjunto de Valencia, una ciudad que como podremos comprobar presenta diversas caras y contrastes.

\section{MAPAS MENTALES: EL ESPACIO PERCIBIDO}

El planteamiento teórico de la Geografía de la percepción y el comportamiento, se basa en admitir que los seres humanos acumulan una serie de imágenes en su mente, existiendo la posibilidad de medirlas o cuantificarlas. Las imágenes ayudan a confeccionar el mapa mental de cada individuo. A partir de ello pedimos a los alumnos universitarios objeto de nuestro trabajo que dibujasen una mapa de la ciudad, primero de forma individual y después en grupos de ocho personas. que deberían ponerse de acuerdo en dibujar un mapa colectivo. En éste debían quedar reflejados los elementos más destacables aportados por todos ellos. De esta forma obtendríamos la forma urbana de la ciudad y los principales elementos que la componen. 
FIGURA 1

MAPA MENTAL DE VALENCIA

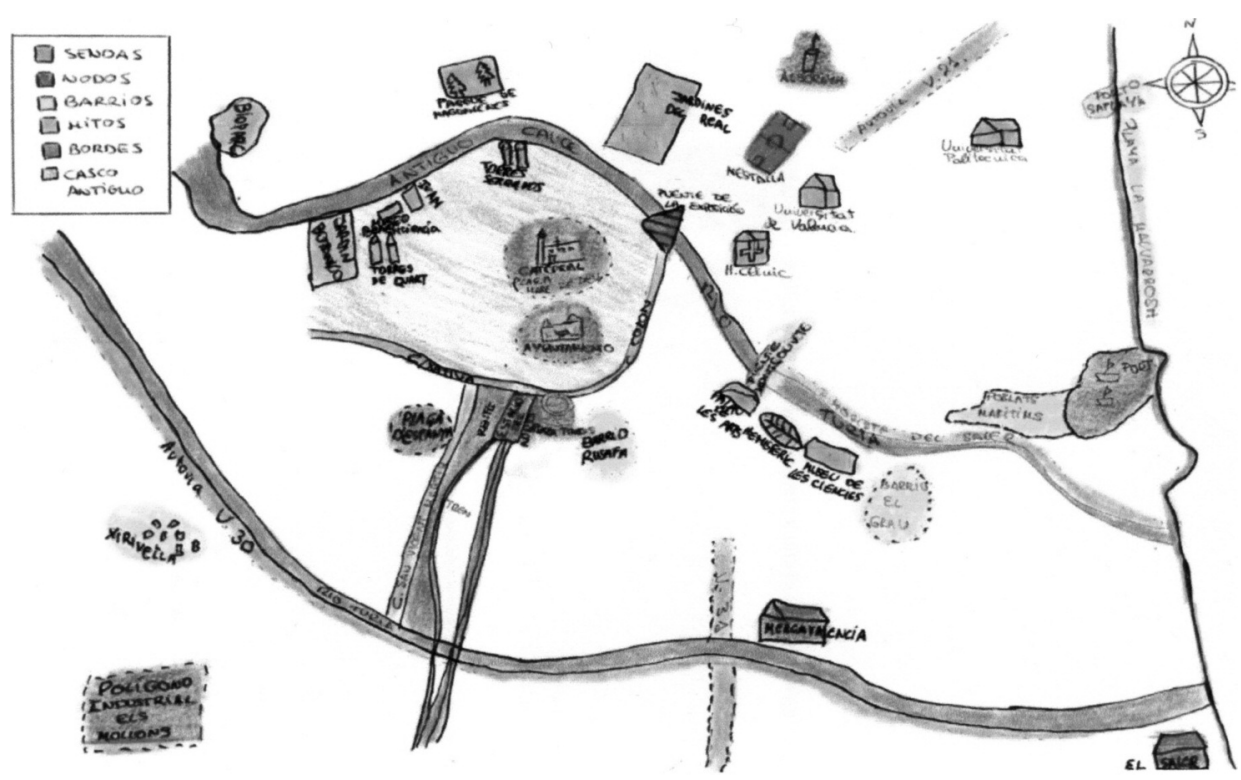

Nota: El alumnado delimita de forma muy significativa las principales sendas, nodos e hitos de Valencia. También identifica en el conjunto urbano el casco histórico y otros espacios que forman parte de la memoria colectiva de los ciudadanos.

Fuente: alumnos universitarios de Valencia (2014).

$\mathrm{Al}$ observar los distintos mapas mentales elaborados, elaboramos un cuadro con los elementos más sobresalientes teniendo como base el planteamiento de Lynch con otras aportaciones posteriores que de alguna forma cuestionan este planteamiento inicial (De Castro, 2005). 
FIGURA 2

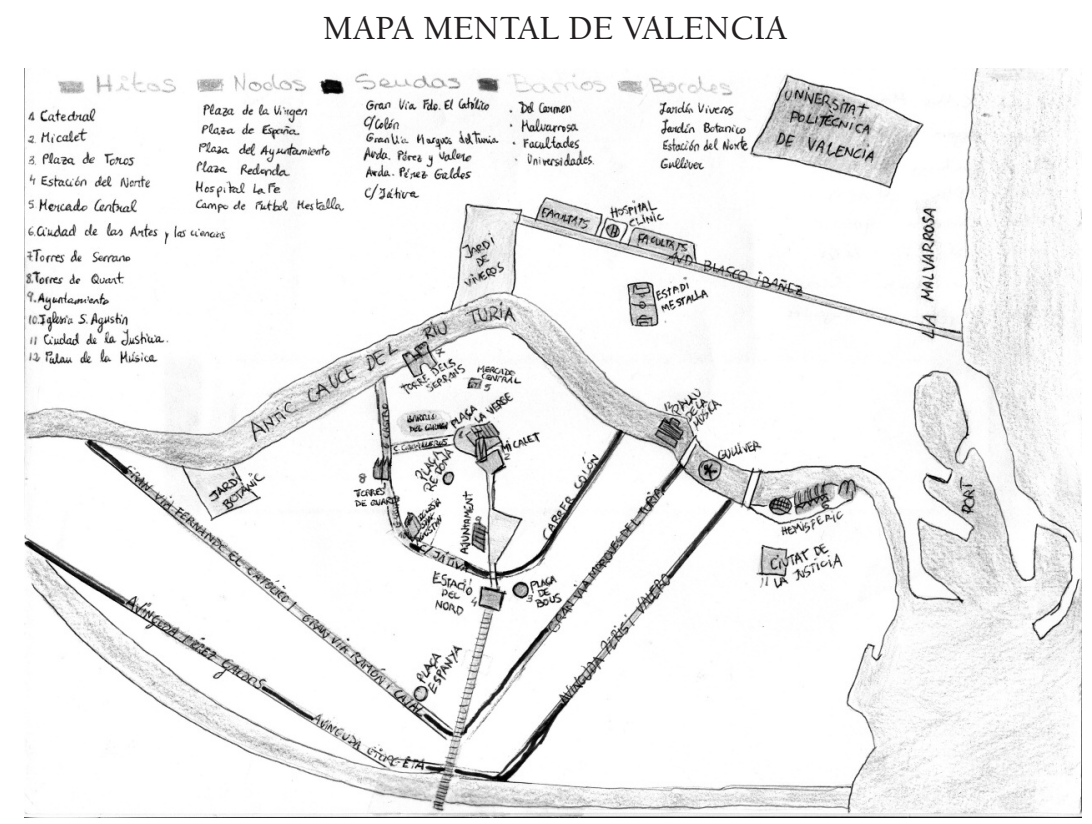

Nota: Destacamos la significativa plasmación de las principales «sendas» de la ciudad, así como los bordes más destacados e hitos más conocidos por este colectivo de estudiantes universitarios.

Fuente: alumnos universitarios de Valencia (2014).

\section{Cuadro 2}

\section{RELACIÓN DE LOS ELEMENTOS MÁS DESTACADOS EN VALENCIA}

\begin{tabular}{llll}
\hline \multicolumn{1}{c}{ Hitos } & \multicolumn{1}{c}{ Nodos } & \multicolumn{1}{c}{ Sendas } & \multicolumn{1}{c}{ Bordes } \\
\hline -Catedral & Plazas de la Virgen, La & Calles de Colón, Guillén & \multicolumn{1}{c}{ Paseo la Pechina, } \\
-Miquelet & Reina, Ayuntamiento, & de Castro, Xátiva, & $\begin{array}{l}\text { De la Alameda, } \\
\text { Avda. Francia, }\end{array}$ \\
-Plaza de Toros & España, Redonda & San Vicente Mártir, Ru- & Aváces Viejo \\
-Ciudad de las & Hospital la Fe Mestalla & zafa, Barón de Cárcer, & Cauces \\
Ciencias y Artes & Universidad & Avda. de Fernando el Ca- & y Nuevo, \\
-Torres de Serrano & Estación del Norte & tólico/Ramón y Cajal, Pé- & red de ferrocarril, \\
-Torres de Quart & Estación autobuses & rez Gáldos/ Giorgeta, Perís & franja marítima: \\
-Ayuntamiento & Jardines del Real & y Valero, Ausías March, & puerto y paseo \\
-Palacio La Música & & Germanías/Marqués del & marítimo \\
-Mercado Central & & Turia, Blasco Ibañez, El & \\
y de Colón & & Puerto & \\
-Puentes sobre & & & \\
el cauce viejo & & & \\
del Turia & & & \\
\hline
\end{tabular}

Fuente: elaboración propia. 


\section{MAPAS PREFERENCIALES}

Consideramos importante la elaboración de un mapa preferencial de la ciudad, para ello mediante encuesta realizamos un sondeo de opinión sobre los barrios de la ciudad. Elaboramos una lista para que señalaran por orden de mayor a menor la estimabilidad residencial los barrios en los que más le gustaría vivir. Del total de barrios seleccionados por cada persona encuestada consideramos los diez primeros clasificados, dando una puntuación máxima de diez al barrio que figura en primer lugar de la lista, nueve al siguiente, y así sucesivamente. A partir de las puntuaciones obtenidas por los diez primeros barrios, una vez efectuada su suma, realizaremos un mapa topológico preferencial. Observamos como a través de los resultados de las encuestas, existen grandes coincidencias en la estimabilidad residencial de muchos barrios, pero también aparecen importantes diferencias de percepción, en función, sobre todo, de los lugares de residencia, de la distancia, de la experiencia personal, de la familiaridad con el medio, del contexto socio-familiar y de los estereotipos generados por el arte, la propaganda y los medios de comunicación de masas.

El resultado de esta encuesta reflejó de forma muy clara las preferencias para vivir o los elementos del paisaje que más arraigo tienen en su mente. En primer lugar presentaremos los resultados del conjunto del grupo sobre las preferencias donde vivir, después seleccionaremos un mapa mental de un alumno sobre la imagen que tiene de la ciudad en su pensamiento. Ambos ejercicios nos ayudarán a conocer mejor las preferencias y a comparar el grado de coincidencia con otros métodos aplicados en el trascurso de este trabajo.

El total de personas que realizaron la encuesta fue superior a 300, aunque finalmente los resultados mostrados corresponden a 274 , a los cuales otorgamos un total de cincuenta puntos de forma individual, según el lugar preferente donde querían vivir, sumados los resultados obtuvimos las puntuaciones, teniendo presente que la ciudad quedó dividida en treinta espacios, de los cuales al final agrupamos por proximidad algunos de ellos, por ejemplo Patraix-Jesús o Puerto-Playas, por lo que centramos nuestro estudios en veinte unidades, que presentan similares características morfológicas A partir de las encuestas realizadas, entrevistas y demás metodología empleada, podemos concluir señalando que la ciudad desde el punto de vista perceptivo podría dividirse en espacios diferenciados por aspectos tan variados como su morfología urbana, su nivel de equipamientos, sus rentas, su cualificación socio-profesional, etc.

Existe una preferencialidad por vivir en los barrios del ensanche que lógicamente son los mejores comunicados, más dotados de infraestructurales comerciales y culturales. 


\section{CUADro 3}

ORDEN PREFERENCIAL DE LOS BARRIOS DE VALENCIA

\begin{tabular}{|c|c|c|}
\hline Nombre del Barrio & $\begin{array}{l}\text { Correspondencia } \\
\text { Distrito censal }\end{array}$ & Puntuación \\
\hline San Francisco & 1 & 1.490 \\
\hline La Seu & 1 & 1.200 \\
\hline Ciudad de las Ciencias y Artes & 10 & 1.080 \\
\hline El Mercado Central & 1 & 1.050 \\
\hline La Xerea & 1 & 930 \\
\hline Gran Vía & 2 & 880 \\
\hline El Botánico & 3 & 820 \\
\hline El Pilar & 1 & 770 \\
\hline Plano del Remedio & 2 & 740 \\
\hline El Carme & 1 & 690 \\
\hline Ciudad Universitaria & 6 & 620 \\
\hline Russafa & 2 & 520 \\
\hline La Malvarrosa & 11 & 440 \\
\hline Malilla & 10 & 380 \\
\hline Mestalla & 6 & 370 \\
\hline Jaume Roig & 6 & 370 \\
\hline Patraix & 8 & 310 \\
\hline El Saler & 19 & 260 \\
\hline Trinitat & 5 & 180 \\
\hline El Perellonet & 19 & 80 \\
\hline San Marcelino & 9 & 80 \\
\hline Monteolivete & 10 & 80 \\
\hline Benimaclet & 10 & 60 \\
\hline Campanar & 4 & 50 \\
\hline Tres Forques & 7 & 50 \\
\hline Benicalap & 16 & 50 \\
\hline Ciudad Jardin & 13 & 40 \\
\hline Arrancapins & 3 & 30 \\
\hline Cabañal & 12 & 30 \\
\hline \multirow[t]{2}{*}{ Pinedo } & 19 & 30 \\
\hline & & 13.680 \\
\hline
\end{tabular}

Fuente: trabajo de campo y elaboración propia. 
FIGURA 3

MAPA PREFERENCIAL DE LOS BARRIOS MÁS DESTACADOS DE VALENCIA

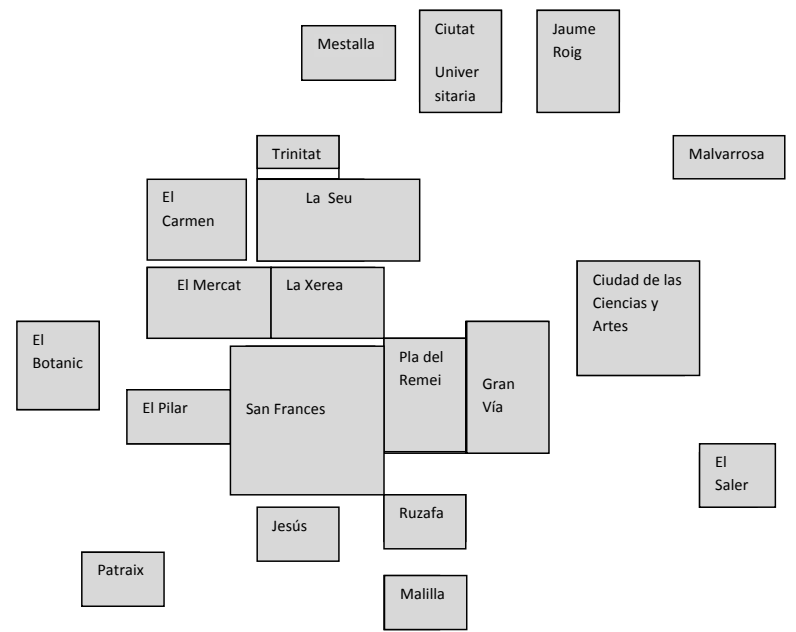

Nota: Las diferentes figuras representan de forma proporcional el grado de preferencialidad y conocimiento de los estudiantes universitarios. El peso del Casco Antiguo con sus diferentes barrios como lugar de ocio y diversión es muy destacado, también el entorno de la ciudad universitaria, la «Ciudad de las Ciencias y Artes» y los nuevos desarrollos urbanos en la franja litoral: puerto, playas, circuito de fórmula 1 y centros comerciales.

Fuente: elaboración propia.

\section{El ANÁliSIS DE LA CIUDAD A TRAVÉS DE LA PERCEPCIÓN DE SUS HABITANTES}

El trabajo de campo realizado nos ayudará a conocer de forma cuantitativa la valoración que hacen los ciudadanos de su ciudad, todo ello basado en un diseño cuasi-experimental, para ello, tal como señalamos en el apartado anterior de metodología, llevamos a cabo una encuesta. Después de tabularla pasamos a mostrar los datos más significativos que sin lugar a dudas invitarán a la reflexión.

\section{Elementos estructurales de la ciudad}

Los Hitos son los elementos del paisaje urbano que la mayoría de sus habitantes utilizan como puntos de referencia y guía, en el caso de la ciudad de Valencia observamos como los principales serían (con casi idéntica puntuación) 
en primer lugar el espacio más modernista y reciente: La ciudad de las Ciencias y las Artes y el recinto de la Catedral y su entorno, que por el contrario es uno de los espacios más antiguos de la ciudad.

Seguidamente aparecen edificios de gran tránsito y utilización por los habitantes como es el Ayuntamiento, la estación del Norte o la contigua plaza de toros. Otros elementos que han sido incorporados en fechas no muy lejanas como el monumento denominado «la Pantera Rosa» en la plaza Manuel Sanchís Guarner/calle Filipinas, que curiosamente ahora es azul, la figura del «Gulliver» dentro del cauce viejo del río Turia, el puente de la estación de La Alameda denominado por su forma «La Peineta» obra del arquitecto Santiago Calatrava, o la «catedral» del futbol valenciano como es el viejo estadio de «Mestalla» ocupan un lugar destacado en la retina de los valencianos, que también señalan la calle comercial de Colón y sus alrededores como un lugar bien conocido y visitado.

GRÁFICO 1

HITOS DESTACADOS DE VALENCIA

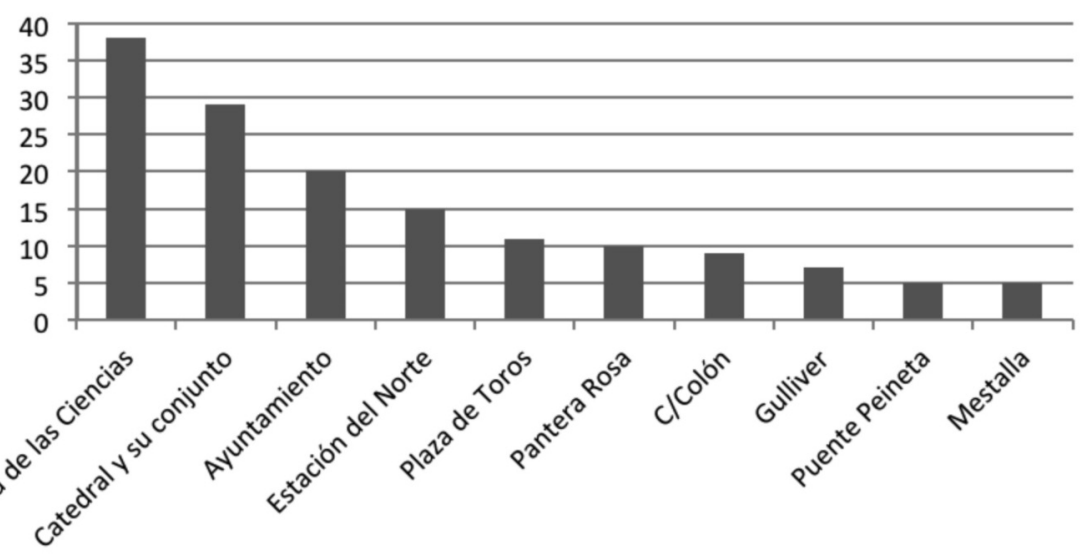

Fuente: elaboración propia.

Las Sendas y Nodos significan los puntos de tránsito y encuentro en la vida de los ciudadanos. A través de las encuestas se identifican perfectamente como sendas las grandes avenidas que organizan de forma geométrica los barrios del ensanche valenciano como Ausías March o Fernando el Católico que 
FOTOGRAFÍA 1

\section{MERCADO CENTRAL DE VALENCIA}

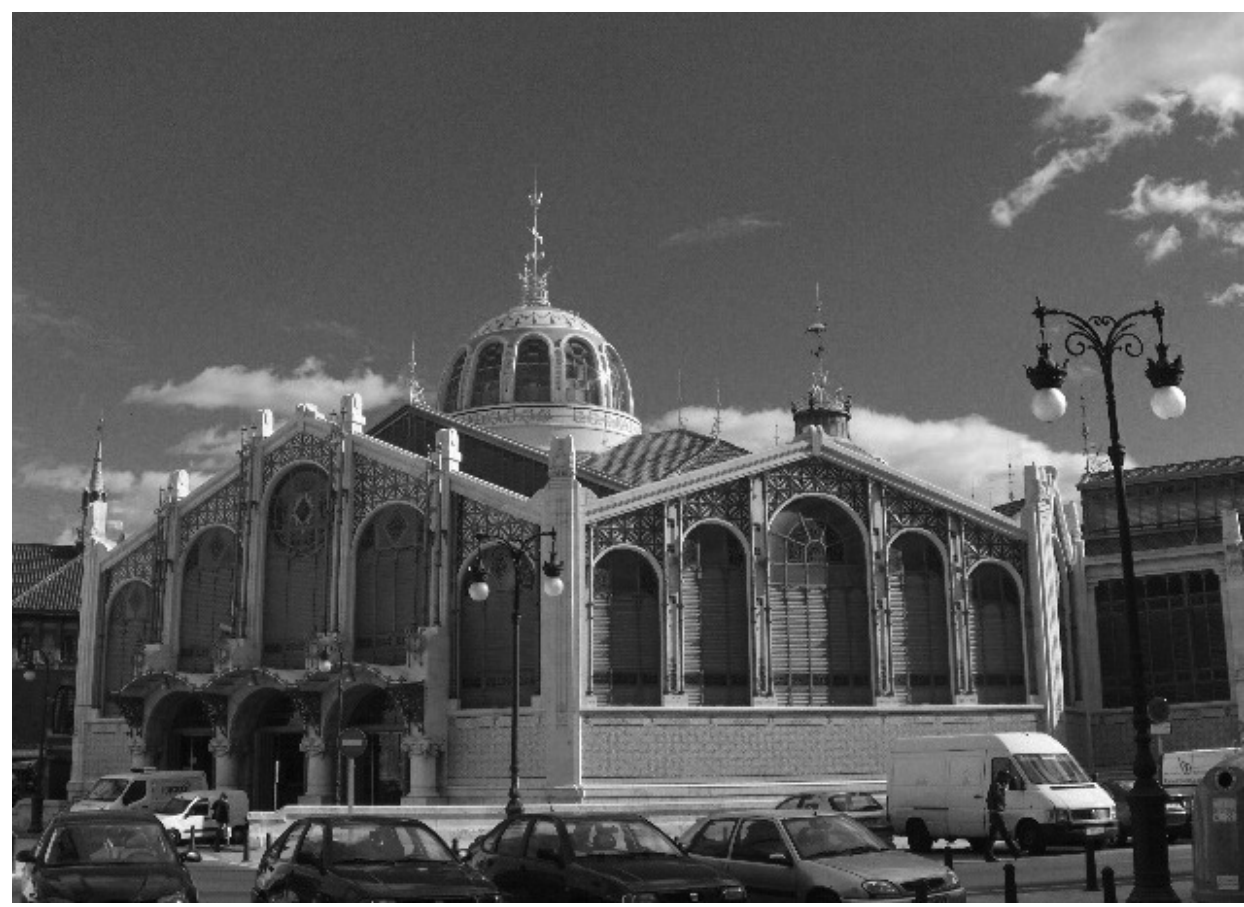

Nota: El mercado central es un hito en ciudad ya que supone un lugar de encuentro dentro del Casco Histórico de Valencia.

Fuente: el autor (2014).

se prolonga por Ramón y Cajal. Los nodos son lugares de encuentro tan emblemáticos como la estación del Norte, las plazas del Ayuntamiento, la Virgen o el Mercado Central. Dentro de la Ciutat Vella, avenidas como Barón de Cárcer, San Vicente Mártir o los límites como son las calles Guillén de Castro, Xátiva, la Pechina o Colón son los espacios reconocidos mayoritariamente.

Respecto a los Bordes o elementos que separan espacios diferenciados morfológica o socialmente, claramente destacamos tanto el cauce viejo o el nuevo del río Turia. También, por supuesto, el eje ferroviario que llega hasta el corazón de la ciudad y que dada la dificultad para un futuro soterramiento parte la ciudad en todo el ensanche sur lo que ha repercutido en un serie de puentes por encima de la misma como Avda. de Peris y Valero o túneles como en el paseo de Germanías-Marqués del Turia. 


\section{FIGURA 4}

\section{PRINCIPALES HITOS SEÑALADOS POR EL ALUMNADO UNIVERSITARIO}

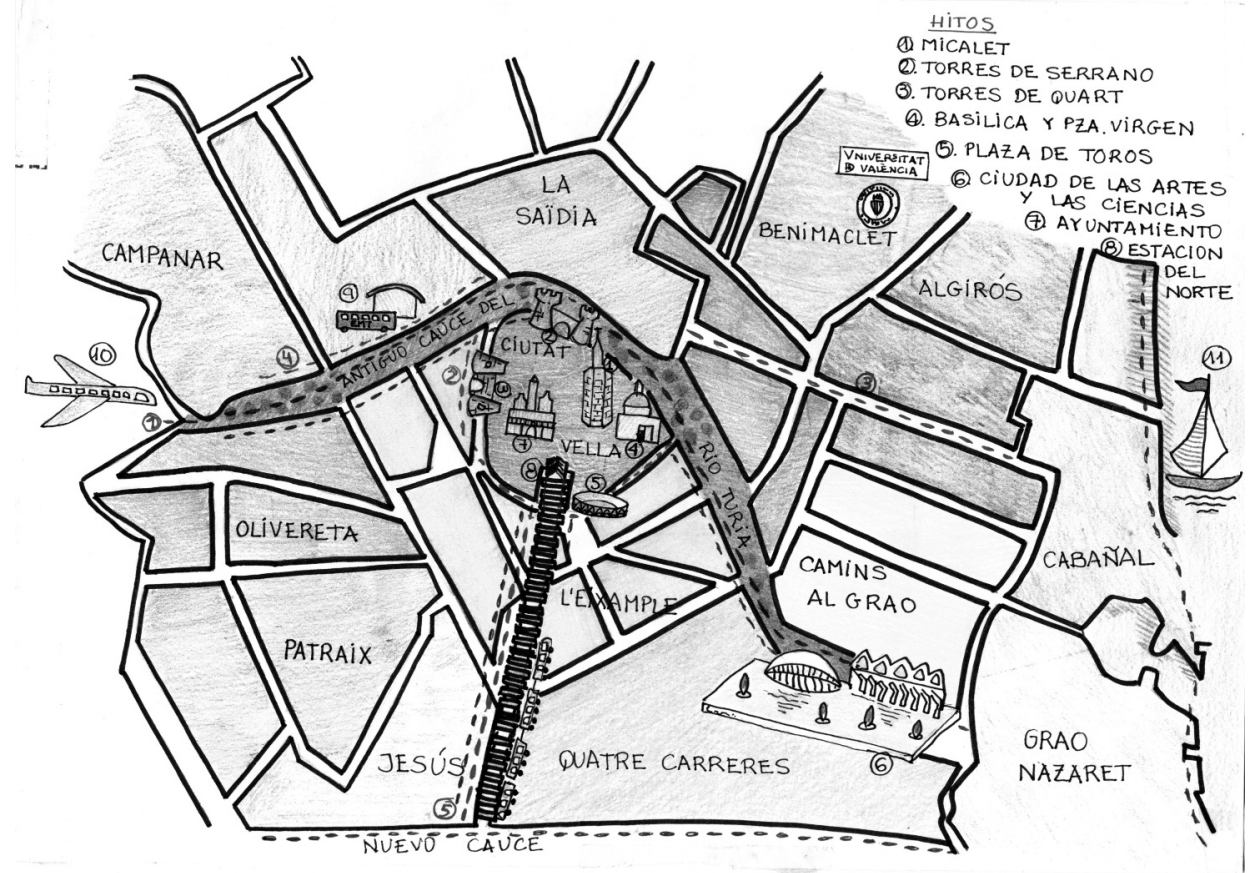

Nota: Destacamos dentro de los hitos en Valencia, como en la memoria colectiva de los estudiantes universitarios aparece la barrera psicológica del corredor ferroviario que arranca en el barrio de Malilla y llega al corazón de la ciudad en la Estación del Norte. También el casco histórico está muy presente en la memoria colectiva y los «bordes» del cauce nuevo y viejo del río Turia.

Fuente: alumnos universitarios de Valencia (2014).

\section{Aspectos que echaría en falta si se marchase de Valencia}

En general para los habitantes de Valencia, su ciudad le parece un lugar atractivo y se muestran orgullosos de la misma, no cabe dudas que la ciudad es un gran centro de compras y ocio. Las tiendas y la oferta lúdica ocupan las preferencias de los valencianos y lo que echarían en falta en caso de trasladarse a otro lugar. A ello hay que sumarle el impacto de las fiestas de Fallas en marzo, las playas y la gastronomía. En menor proporción, destacan la presencia de los monumentos, casco histórico o zonas verdes. 
GRÁFICO 2

ELEMENTOS QUE ECHARÍA EN FALTA AL MARCHARSE DE VALENCIA

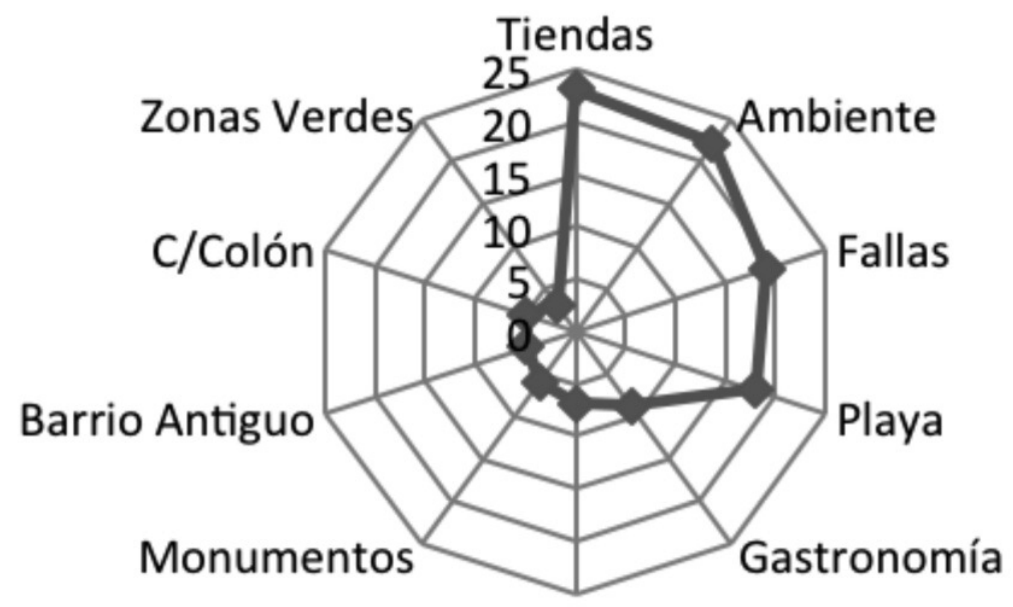

Ciudad de las Ciencias

Fuente: elaboración propia.

Lugares que mostraría en caso de tener que mostrar la ciudad

Los encuestados de Valencia en un alto grado de satisfacción se siente orgulloso de su ciudad y de las posibilidades que ofrece a sus habitantes tanto culturales como recreativas, destacada la preferencia por lo monumental, de ahí que se señalen un $45 \%$ de los mismos que sería imprescindible en caso de visitar la ciudad visitar la catedral y su entorno, a continuación un $42 \%$ indica la Ciudad de las Ciencias para pasar después al espacio de playas (22\%) y volver de nuevo al casco antiguo con un $17 \%$. Sorprende el contraste entre el casco antiguo y el entorno de la Catedral, muy probablemente por el diferente estado de conservación, que, a pesar de los esfuerzos realizados, todavía presenta graves deficiencias. Hay muchas casas con expediente de ruina y edificios emblemáticos demolidos, por ejemplo, el teatro de la Princesa, que fue demolido tras un incendio.

También son espacios para «enseñar» los edificios singulares situados en el distrito uno o "Ciudad Vella» tales como la fachada del ayuntamiento, mercado central, estación del Norte, o jardines del Turia. 
Fuera del centro urbano destacamos la Albufera-Saler, se trata de un parque natural protegido de gran valor ecológico y con una playa de cinco kilómetros de longitud con dunas y pinares que protege el arenal de los vientos de poniente. Por otro lado la playa de la Malvarrosa tiene un larga tradición desde principios del siglo xx, quedó inmortalizada por los cuadros de Sorolla y la literatura de Blasco Ibañez, actualmente en época estival ha recuperado una gran vitalidad con numerosos chiringuitos en el paseo marítimo, también la celebración de la Copa América o el circuito de fórmula Uno (en estos momentos muy cuestionado por la viabilidad económica) han sido actividades que han ofrecido posibilidades de negocio a la zona. Pero, ciertamente, todavía el valenciano no está orgulloso de sus playas sino del hecho de tenerlas.

GRÁFICO 3

LUGARES PREFERENTES PARA MOSTRAR DE VALENCIA

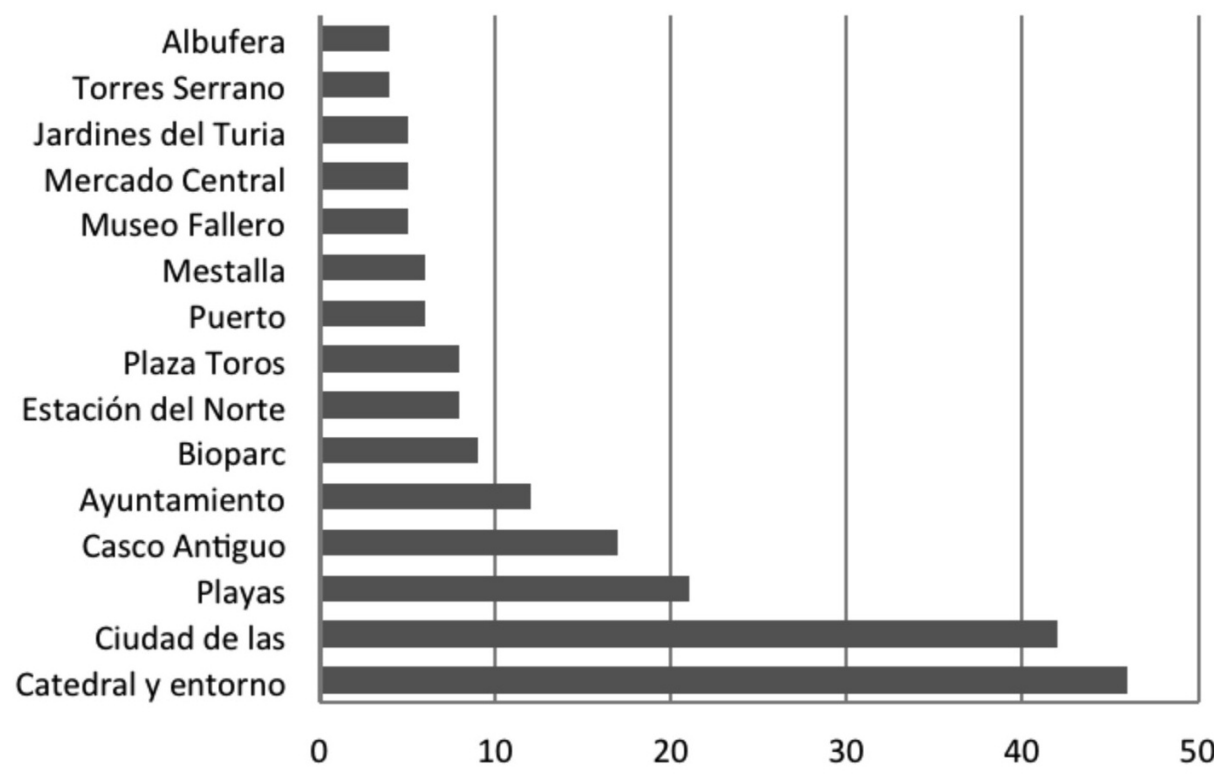

Fuente: elaboración propia. 


\section{Utilización del centro urbano de Valencia: «La Ciutat Vella»}

La ciudad Vella o distrito número uno es el auténtico corazón de la ciudad $\mathrm{y}$ al preguntarle a sus habitantes por la misma señalan que la principal utilización está relacionada esencialmente con las compras (38\%) y diversión (25\%), quedando mucho menos considerado el paseo o la visita a los monumentos existentes. Evidentemente la densificación comercial de un tamaño medio-pequeño es la más alta de la ciudad y compite con los grandes espacios comerciales creados en zonas más externas como el centro comercial del Saler, «Nuevo Centro» o Campanar.

El trazado irregular de la ciudad identifica perfectamente esta área urbana del resto de la misma. Al norte del antiguo cauce del río Turia, con elementos diferenciadores o puertas de entrada de la extinguida muralla como serían las Torres de Serrano; al sur, el trazado de las calles Játiva o Guillén de Castro en donde se sitúan las Torres de Quart delimitan perfectamente el barrio antiguo de Valencia, un espacio singular, perfectamente definido, el cual que alberga

\section{GRÁFICO 4}

GRADO DE UTILIZACIÓN DEL CENTRO URBANO DE VALENCIA

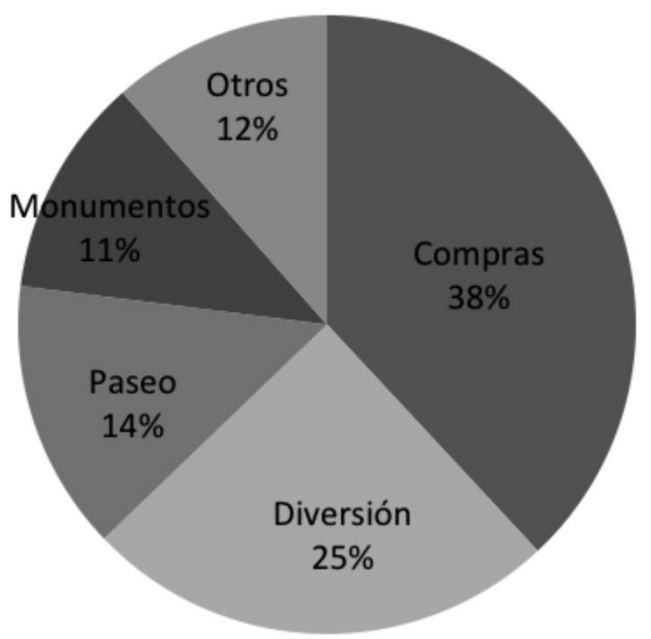

Fuente: elaboración propia. 
los principales monumentos de la ciudad y el mayor atractivo patrimonial con edificios emblemáticos como son la Catedral, Ayuntamiento o plazas singulares como la «Redonda» de la «Virgen» o de la «Reina» Destacamos dentro de la Ciutat Vella los barrios de San Francisco, La Seo, El Mercado, La Xerea, El Pilar y El Carmen.

En las últimas décadas ha existido un importante esfuerzo de recuperación de la Ciutat Vella: un espacio degradado por la falta de accesibilidad y antigüedad del parque inmobiliario. De hecho, son muchas las calles rehabilitadas, y una población en muchos casos envejecida y en otros dedicada a actividades marginales, como la prostitución o las drogas, ha dado paso a la llegada de otros grupos sociales de mayor estatus social y económico. Hasta hace pocos años, algunas viviendas presentaban unos servicios básicos individuales en precario estado: servicios higiénicos, o agua corriente (Gaja, 2009)

El Centro histórico de Valencia está vinculado al rango que ocupa esta ciudad en la jerarquía de las principales sedes de la administración central, autonómica y municipal (equipamientos como la Bolsa, oficinas de entidades financieras, multinacionales, etc.). También es sede Arzobispal, militar y está próximo a un gran nudo de comunicaciones como son el ferrocarril de alta velocidad que la une con Madrid a través de la nueva estación Joaquín Sorolla, el aeropuerto de Manises o el Puerto marítimo.

En relación al estado de conservación de las construcciones, se observa a través de las memorias económicas del «Plan de rehabilitación integral de Valencia» (RIVA) diversas inversiones realizadas en la conservación de los edificios más emblemáticos que en general presentan tras esta intervención que comenzó hace más de dos décadas un mejor estado de conservación, por el contrario muchos bloques de viviendas y casas de tipo residencial todavía presentan importantes déficits estructurales que en parte han sido remodelados por diversos planes de rehabilitación. El plan RIVA iniciado en 1992 hasta 2002, aportó la intervención en un área de una extensión aproximada de $1.730 .000 \mathrm{~m}^{2}$ con cinco grandes objetivos:

- Rehabilitar y revitalizar el barrio antiguo

- Mantener la población, en general envejecida lo que ha llevado a la necesidad de atraer a otros colectivos y que ha repercutido en la instalación de una importante población de personas inmigrantes que generalmente han ocupado en régimen de alquiler los edificios con peores condiciones higiénico-sanitarias. 
- Instalación de servicios de carácter social como centros de salud y espacios de atención a la tercera edad.

- Búsqueda de participación de la ciudadanía en este proceso, en este sentido ha participado diversas asociaciones de vecinos.

- A través de la intervención pública se pretendía buscar el atractivo de la iniciativa privada, lo que ha repercutido en una mejora sustancial de algunas calles.

Las actuaciones llevadas a cabo, dieron como resultado la paralización del proceso de degradación y entre otros se realizaron mejoras de habitabilidad en fachadas, cubiertas y elementos comunes de 3.500 viviendas, se instalaron 45 equipamientos con fines sociales y se regeneraron $49.704 \mathrm{~m}^{2}$ de espacios públicos con la consiguiente reurbanización de calles, nuevos espacios públicos, modernización de servicios de energía eléctrica, telefonía, canalización de aguas y alcantarillado (Dolc, 2009)

FOTOGRAFÍA 2

PLAZA DE COLL

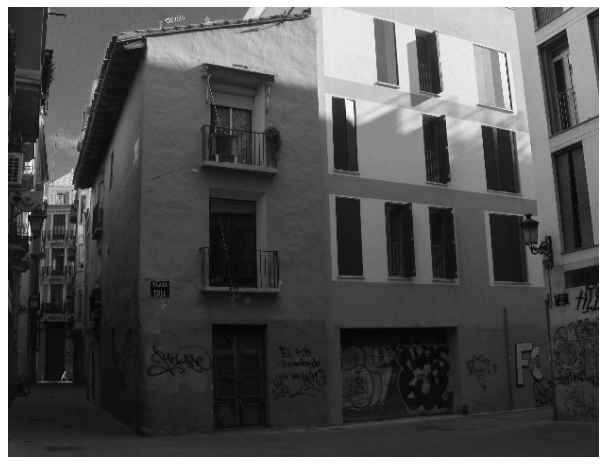

Nota: Contraste entre viviendas rehabilitadas y Abandonadas en Ciutat Vella.

Fuente: el autor (2014).
FotogRAFÍA 3

CALLE BOTELLAS

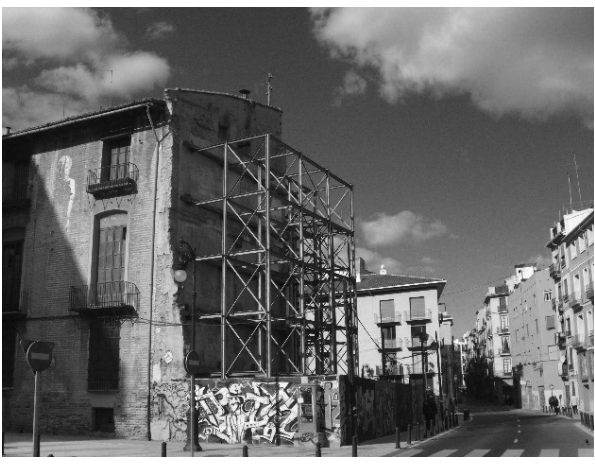

Nota: En Ciutat Vella todavía existen muchos inmuebles en estado de abandono o en ruinas. Fuente: el autor (2014). 
FIGURA 5

\section{LOCALIZACIÓN DE LOS PRINCIPALES USOS PÚBLICOS EN LA CIUTAT VELLA}

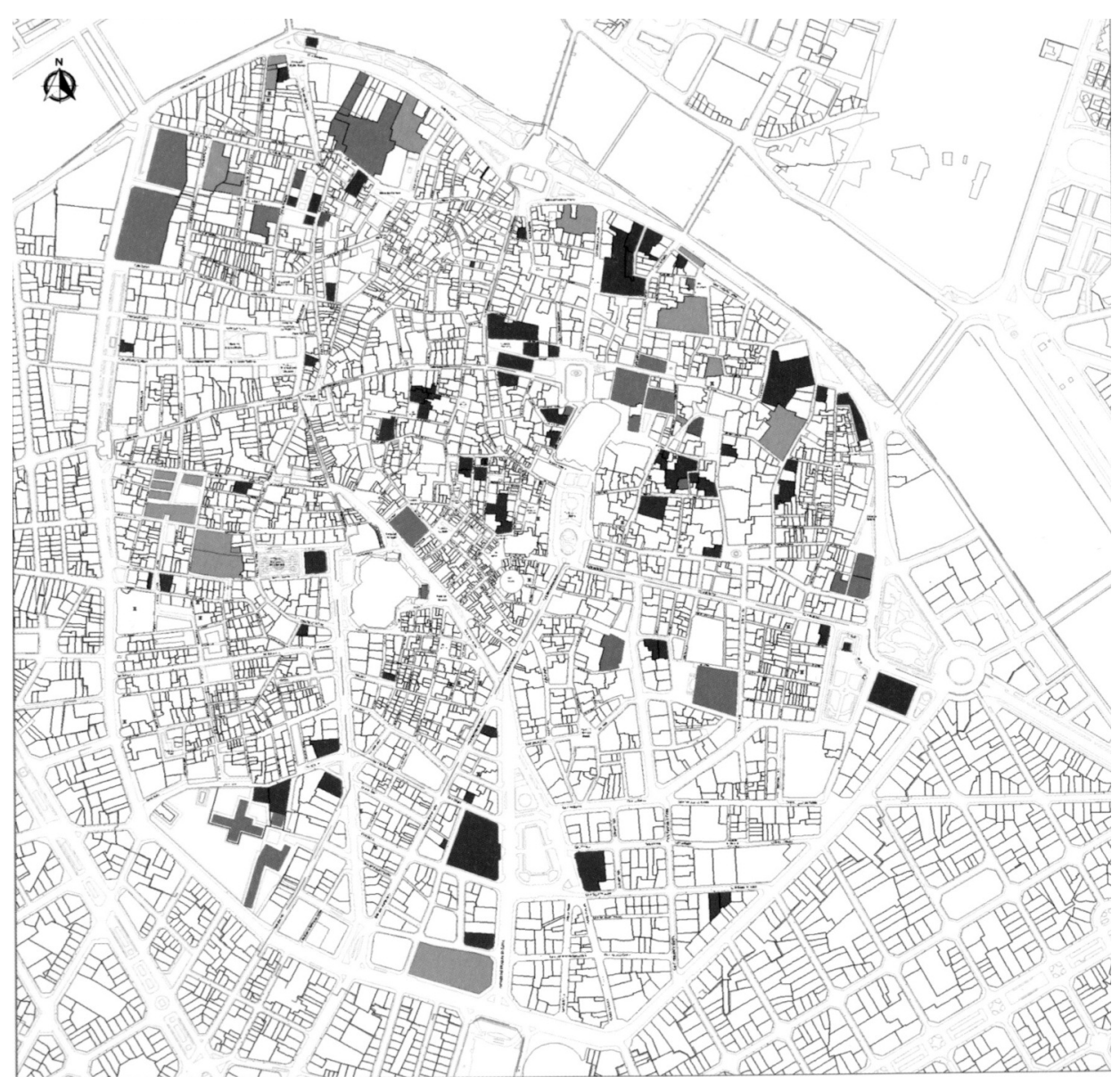

Nota: El Casco histórico de Valencia o Ciutat Vella alberga un importante número de equipamientos públicos: sedes institucionales, centros asistenciales y sociales, equipamientos culturales, escolares y deportivos. Todo ello ayuda en la dinamización de un barrio con clara tendencia al envejecimiento poblacional y en determinados espacios a la concentración de un sector de población marginal.

Fuente: F. Gaja (2004). 


\section{La movilidad a través de los medios de transporte}

Valencia, es una ciudad muy amplia, extensa; la movilidad como ocurre en las grandes ciudades en un elemento muy importante para sus habitantes, en las encuestas realizadas sobre el medio de transporte utilizado muchos ciudadanos se decantan por orden de preferencia entre el metro y autobús como uso colectivo, también curiosamente se deambula bastante, por el contrario el uso de la bicicleta como medio de transporte ecológico y barato es casi testimonial a pesar de existir un servicio público de bicicletas de alquiler en diferentes puntos de la ciudad. Respecto al automóvil y motocicleta son muy frecuentados, de hecho en la ciudad dada la particularidad de su callejero son importantes los atascos en las horas punta, a lo que une un ritmo de desplazamiento muy rápido especialmente en la grandes avenidas como Fernando el Católico, Peris y Valero o Avda. del Puerto entre otras.

GRÁFICO 5

PREFERENCIALIDAD EN LA UTILIZACIÓN DEL TRANSPORTE

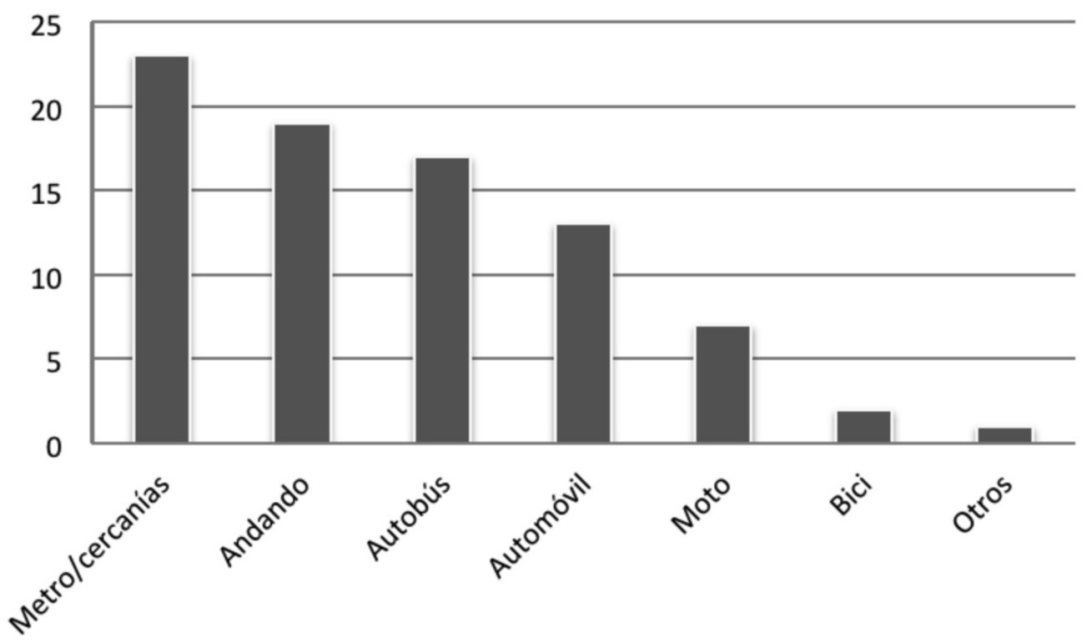

Fuente: elaboración propia.

Estudios Geográficos, Vol. LXXVI, 278, pp. 203-33, enero-junio 2015

ISSN: 0014-1496, eISSN: 1988-8546, doi: 10.3989/estgeogr.201507 


\section{Los sentidos emocionales del lugar}

Entre el individuo y el espacio habitual de residencia existen relaciones emocionales que se expresan a través del sentido del lugar y repercuten en el comportamiento de los ciudadanos (Zárate, 2012), de hecho en los ciudadanos se puede generar un sentido positivo de unión e identificación con el espacio en donde se vive o por el contrario negativo y rechazo. Yi Fu Tuan (1974), desde un enfoque fenomenológico ha intentado reconstruir de forma empática cómo los vecinos expresan esos sentimientos en relación al lugar: de topofilia o simpatía, de topolatría o sentido reverencial y mítico, de topofobia o aversión, rechazo y miedo, y de toponegligencia o desinterés cuando el lugar carece de interés. Evidentemente todos ellos guardan relación con la subjetividad.

Para el caso de la ciudad de Valencia, destacamos como lugares de topofília la Plaza del Ayuntamiento como espacio en donde se instala la falla mayor, la

\section{Fotografía 4}

\section{FACHADA CENTRAL DE «LA LONJA»}

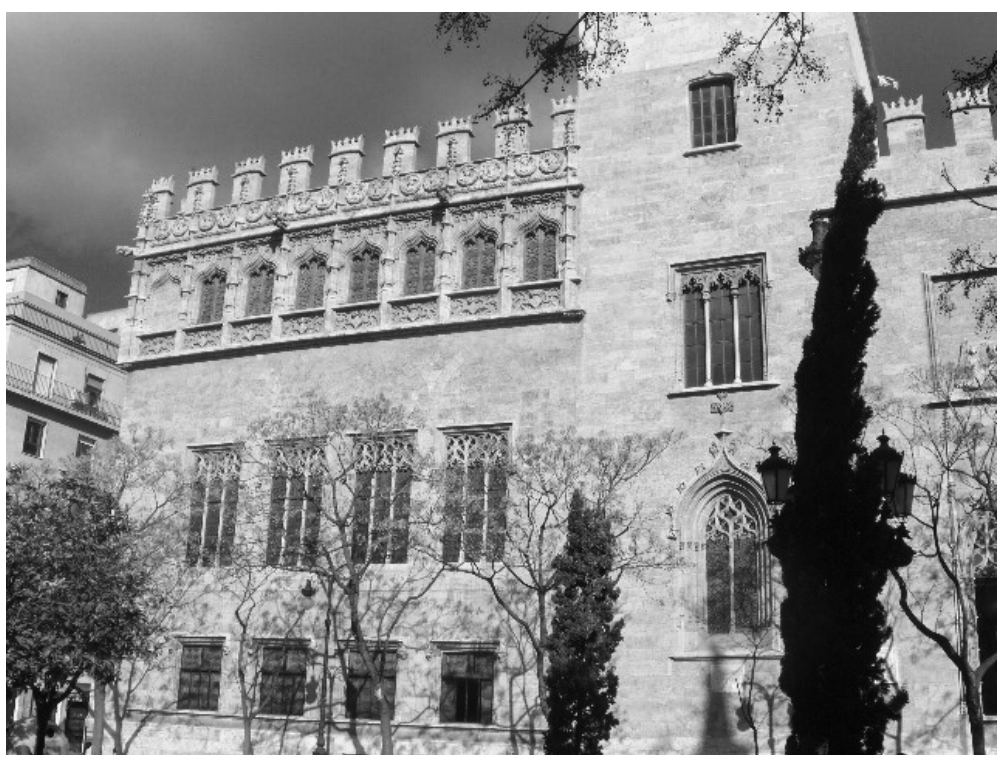

Nota: La antigua Lonja de Valencia constituye un importante hito en el paisaje cultural del casco histórico de Valencia y es uno de los principales lugares de visita turística en la ciudad.

Fuente: F. Morales (2014). 
catedral y la plaza de la Virgen como espacio de espiritualidad. También se suma a ello la recién construida Ciudad de las Artes y Ciencias y los espacios verdes construidos dentro del cauce viejo del río Turia y jardines colindantes. Finalmente la estación del Norte y plaza de toros, antigua lonja y mercado Central son también espacios muy queridos por la mayoría de los encuestados.

En relación a los espacios que levantan un sentido más reverencial destaca en primer lugar la catedral y su entorno, así como las plazas adyacentes y espacios cercanos como los palacios de la Generalitat o las Cortes, o como la puerta norte de entrada a la ciudad que sería las Torres de Serrano.

Los espacios más rechazados corresponden a las barriadas creadas como poblados de absorción en los años 60 del siglo xx, en ellos vive una población de bajas rentas y extracto social en muchas ocasiones marginal, donde aparecen situaciones de delincuencia y menudeo de drogas, destacamos barrios como Lacoma, La Fuensanta, La Luz e incluso a pesar de las obras de remodelación en los poblados marítimos de El Cabañal, Nazaret o El Grao quedan importantes bolsas de pobreza y prostitución, lo cual contrasta con el esplendor de la ciudad y reclama actuar con urgencia para recuperar estos espacios todavía degradados.

Por último respecto a los barrios en donde existe una indiferencia o desinterés de la población serían aquellos menos transitados, desconocidos y generalmente impersonales, con falta de equipamientos comunes como zonas verdes, espacios deportivos y culturales; con una baja calidad de la construcción como elemento más común y la preferencialidad por vivir en ellos es escasa aunque algunos poco a poco se van recuperando, tal es el caso de La Fuente de San Luis, en donde la proximidad del nuevo hospital de la Fe y la Ciudad de las Ciencias, así como la construcción de un gran pabellón polideportivo están ayudando mucho, como queda reflejado en las encuestas.

Como podemos comprobar en el cuadro y gráfico que presentamos a continuación, los elementos materiales como la Ciudad de las Ciencias, Casco histórico, cauce viejo del río Turia y Bioparc son los más señalados; mientras que los elementos inmateriales como la fiesta de Fallas, Clima, gastronomía y compras son preferenciales en la forma de vivir y entender la ciudad. 


\section{CuAdro 4}

VALORACIÓN DE LOS LUGARES Y SENTIDOS PREFERENCIALES DE LOS CIUDADANOS DE VALENCIA

\begin{tabular}{|c|c|c|c|c|c|c|}
\hline & Valor 0 & Valor 1 & Valor 2 & Valor 3 & Valor 4 & Valor 5 \\
\hline Albufera & & & 3 & 13 & 16 & 15 \\
\hline Bioparc & & 1 & 2 & 6 & 16 & 22 \\
\hline Casco Histórico & & 1 & 1 & 5 & 14 & 26 \\
\hline Ciudad Ciencias & & & 3 & 6 & 4 & 34 \\
\hline Clima & & & 3 & 4 & 13 & 27 \\
\hline Puerto & & 3 & 5 & 8 & 23 & 8 \\
\hline Compras & & 1 & 1 & 6 & 12 & 27 \\
\hline Feria & & & 1 & 6 & 23 & 17 \\
\hline Gastronomía & & & 2 & 5 & 18 & 22 \\
\hline Cauce viejo & & & 1 & 11 & 14 & 21 \\
\hline Fallas & & & 2 & 4 & 5 & 36 \\
\hline Museos & & 1 & 2 & 7 & 21 & 16 \\
\hline Ocio & & & 1 & 5 & 22 & 19 \\
\hline \multirow[t]{2}{*}{ Playas } & & & & 7 & 12 & 28 \\
\hline & 0 & 7 & 27 & 93 & 213 & 318 \\
\hline
\end{tabular}

Lógicamente la relación de valores sería desde 0 (nula valoración), 1 (muy baja), 2 (baja), 3 (media), 4 (alta) y 5 (muy alta).

Fuente: elaboración propia.

\section{GRÁFICO 6}

\section{VALORACIÓN DE LOS LUGARES Y SENTIDOS PREFERENCIALES DE LOS CIUDADANOS DE VALENCIA}

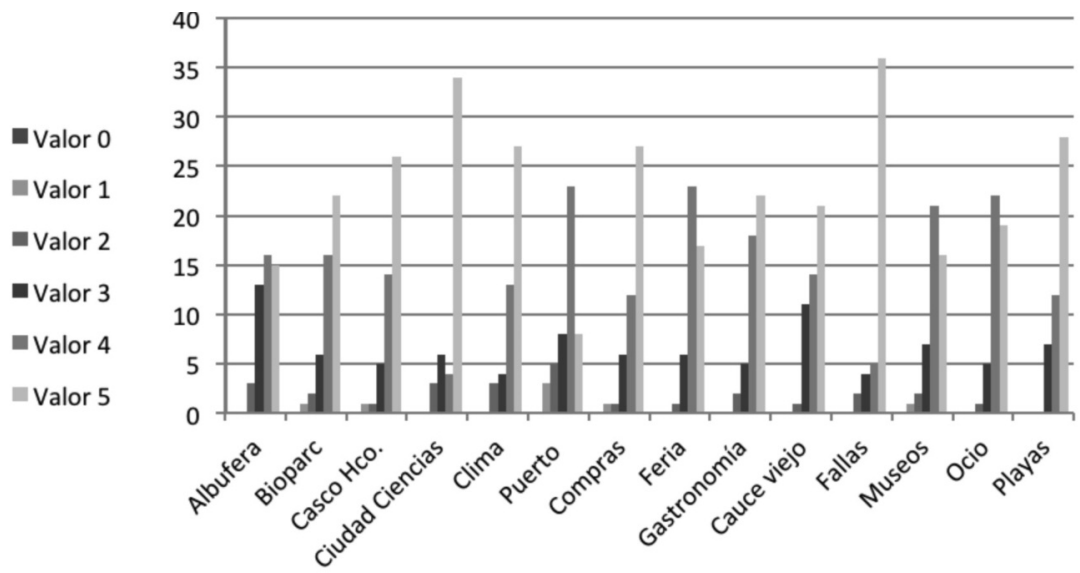

Fuente: elaboración propia. 


\section{CONCLUSIONES}

La geografía de la percepción abre interesantes líneas de investigación que aportan utilidad al conocimiento de la ciudad y presentan la valoración del ciudadano del medio en el que ejerce su actividad cotidiana. Se pueden llevar a cabo propuestas de trabajo encaminadas a potenciar la visión del paisaje urbano, su patrimonio; por todo ello el estudio del espacio geográfico tiene como elemento clave al ser humano y su relación con el medio que le rodea (Gutiérrez, 1996) de ahí la influencia del comportamiento del mismo en relación al cómo perciben su entorno ante un mundo que evoluciona de forma.

En el caso de Valencia queda reflejado por los participantes en este trabajo (estudiantes universitarios) que el grado de satisfacción de la ciudad en la que viven es medio-alto, se reconocen los esfuerzos realizados en la últimas décadas por ir recuperando la ciudad y mejorando sus distintos equipamientos: culturales, deportivos, recreativos o de transporte; no obstante queda mucho por hacer ya que la ordenación del tráfico rodado, la mejora de la accesibilidad o la falta de equipamientos en muchos barrios es todavía deficiente. Se menciona la mejora sustancial del barrio antiguo ya que está siendo más habitable y atractivo por los ciudadanos puesto que hasta hace poco tiempo era considerado un lugar peligroso e insalubre.

Es necesaria una política en la mejora global de algunos barrios que continúan en un imparable proceso de degradación, por ejemplo Ruzafa o zonas de los poblados marítimos como el Cabañal, mientras que otros como el entorno de Ciudad de las Ciencias y las Artes han experimentado un gran atractivo urbano que ha repercutido en la movilidad interna de los ciudadanos.

Los principales hitos se encuentran en el barrio antiguo y las zonas limítrofes al mismo, de hecho la Ciutat Vella junto a la ciudad de las Ciencias y Artes son los espacios más visitados y recordados por los habitantes de Valencia, se pueden combinar edificios emblemáticos como el Miquelet, las fachadas de la catedral, ayuntamiento, estación del Norte, torres de Quart o Serrano con otros tan modernos como el Hemisferic, Museo Príncipe Felipe, Palacio de las artes o puente de la «Peineta».

Los «nodos» principales se localizan alrededor de las grandes rondas de circulación de la ciudad como la estación del Norte en la calle Játiva, así como las principales «Sendas» se localizarían en las grandes avenidas como Fernando el Católico, Germanías, Peris y Valero o Ramón y Cajal; sin olvidar el gran corredor ferroviario que abre una profunda brecha en los barrios del sur hasta el límite con el casco histórico y que denota una aspiración de los ciudadanos desde hace muchos años: el soterramiento de la vías, lo que supondría 
una mejora en la cohesión espacial, movilidad y creación de nuevos desarrollos espaciales.

Valencia es una ciudad marítima, por ello uno de sus principales «bordes» sería el mar, a pesar de las grandes reformas realizadas en el Puerto, todavía queda mucho por hacer en los denominados «poblados marítimos» puesto que perceptivamente muchos ciudadanos todavía tienen la sensación de que son espacios degradados y marginales lo que repercute en una imagen negativa de un espacio que deberá tener gran proyección en el futuro de la ciudad.

Por el contrario la adecuación del viejo cauce del río Turia como espacio de ocio y recreación ha sido uno de los grandes proyectos que ha hecho de la ciudad un espacio más atractivo y referente a nivel nacional e incluso internacional. Por supuesto el cauce nuevo del río Turia en el sur sería otro espacio que

\section{FOTOGRAFÍA 5}

\section{EL PUERTO DE VALENCIA}

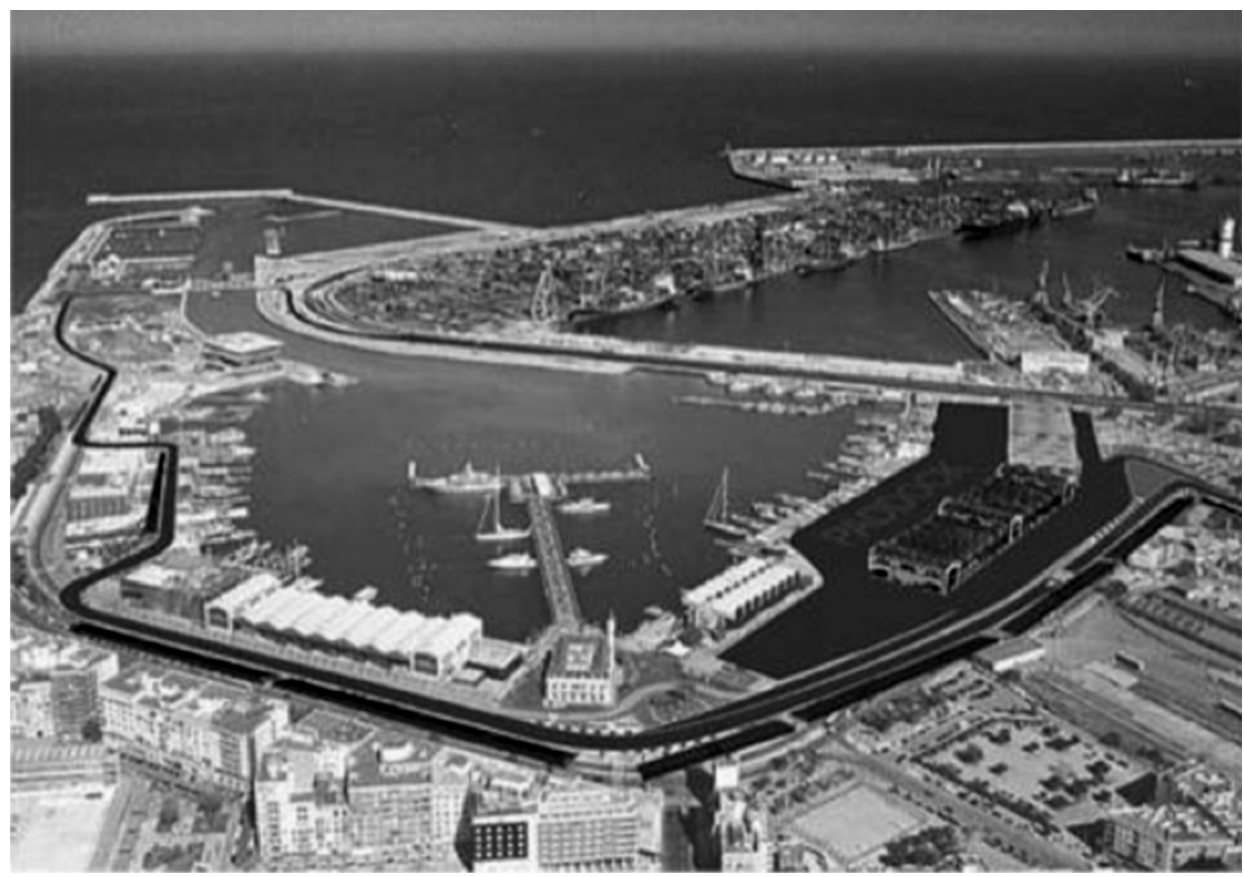

Nota: El puerto de Valencia tras su remodelación para eventos deportivos como la Copa América y la creación del circuito urbano de fórmula Uno, supone un espacio para la ciudad muy dinámico y atractivo. Fuente: nauticajonkepa.wordpress.com 
limita la ciudad con otros municipios como Silla, Picassent y de alguna manera separa la gran aglomeración urbana con la existencia de espacios de huerta, en donde evidentemente se ha formado un neopaisaje que ha ido borrando la imagen casi idílica de los campos de cultivos llenos de naranjos y todo tipo de cultivo hortofrutícolas; sin olvidar la idiosincrasia de los paisajes formados por la presencia del agua: acequias, adarves, y norias elevadoras.

Fecha de recepción: 14 de mayo de 2013.

Fecha de aceptación: 8 de agosto de 2014.

\section{BIBLIOGRAFÍA}

Boira, J. V. (1992): La ciudad de Valencia y su imagen pública. Valencia, Departamento de Geografía. Universidad de Valencia. 1992. 206 pp.

Boira, J. V. (1997): "Reseña del libro de Constancio de Castro, La Geografía en la vida cotidiana. De los mapas cognitivos al prejuicio regional". Biblio 3W. Revista Bibliográfica de Geografía y Ciencias Sociales, 127, www.ub.es/geocrit/b3w-127.htm (Verificada el 27/04/2015).

Bosque, Joaquín y otros (1992): Prácticas de Geografía de la percepción y de la actividad cotidiana. Barcelona. Ed. Oikos-Tau.

Castells, Manuel (1979): La cuestión urbana. Madrid, Siglo XXI.

De Castro, Constancio (1995): "El análisis urbano bajo una perspectiva comportamental", en Aurora García Ballesteros (coord.): Geografía Urbana: La ciudad objeto de estudio preliminar. Madrid, Ed. Oikos-tau.

De Castro, Constancio (1999): "Los mapas cognitivos, qué son, cómo explorarlos". Scripta Nova, 33. http://www.ub.edu/geocrit/sn-33.htm (verificada el: 27-04-2015)

De Castro, Constancio (2005): "Geografía de la percepción como instrumento de planeamiento urbano y ordenación territorial", http://www.cervantesvirtual.com/obra /geografa-de-la-percepcin-como-instrumento-de-planeamiento-urbano-y-ordenacin-territorial-0/ (Verificada el: 27/04/2015)

Dolc, César (2009): "Reflexiones sobre la situación de la vivienda en Ciutat Vella", en Fernando Gaja (coord.): Un futuro para el pasado: un diagnóstico para la Ciutat Vella de Valencia, Valencia, Universidad Politécnica de Valencia, pp. 61-100.

Estébanez, José (1979): “Consideraciones sobre la geografía de la percepción”. Revista Paralelo 37, 3, pp. 5-22

Gaja, Fernando (2009): Un futuro para el pasado: un diagnóstico para la Ciutat Vella de Valencia. Valencia, Universidad Politécnica de Valencia.

Gutiérrez, Carlos y Peña, Jaime (1996): "La percepción geográfica como factor en el desarrollo local Última Década": http://www.redalyc.org/articulo.oa?id=19500412 (verificada el 27-04-2015). ISSN 0717-4691. 
Lynch, Kevin (1960): The image of de city. Cambridge, MIT Press. Edición castellana: (1966): La imagen de la ciudad. Buenos Aires, Ed. Infinito, 194 pp.

Millán, Mercedes (2004): "La geografía de la percepción: una metodología de análisis para el desarrollo rural". Revista Papeles de Geografía, 40, pp. 133-149.

Morales, F. J. (2012): "La geografía de la percepción: una metodología válida aplicada al caso de una ciudad de tipo medio-pequeño. El ejemplo de Yecla (Murcia)". Revista Papeles de Geografía, 55-56, pp. 137-152.

Pocock, D. and Hudson, R. (1978): Images of the urban environment. New York, Columbia University Press.

Reques, P. y otro (1992): "Balance crítico de dos décadas de geografía de la percepción en España. A propósito de los estudios sobre espacios urbanos", en: Actas del V coloquio de Geografía cuantitativa. Zaragoza, Universidad de Zaragoza, pp. 341-356.

Reques, Pedro (2006): "La geografía de la percepción y del comportamiento: Una introducción", en Actas V Jornadas nacionales de investigación en psicología, Santander (http://www.psicologiajoven.com/publicaciones5/Geografia\%20de\%20la\%20percepcion.pdf (verificada el 27-04-2015)

Somoza, José (2006): "La geografía de la percepción como instrumento de ayuda al planeamiento urbano. Un posible ejemplo en la ciudad de orense", en: II Jornadas de Geografía Urbana. Alicante, Biblioteca virtual, pp. 307-314.

Vara, J. L. (2008): “Cinco décadas de Geografía de la percepción”. Revista Ería, 77, pp. 371-384.

Vara, J. L. (2010): “Análisis de textos en Geografía de la Percepción: Estado de la cuestión y bases conceptuales”. Revista Baética, pp. 127-146.

Vara, J. L. (2010): "Una análisis necesario: Epistemología de la Geografía de la Percepción". Revista Papeles de Geografía, 51-52, pp. 337-344.

Zárate, M. A. (1986): "Una aproximación a la geografía de la Percepción". Revista Didáctica Geográfica, 14, pp. 43-64.

Zárate, M. A. (2012): Geografía Urbana. Madrid. Ed. Ramón Areces.

\section{RESUMEN}

El análisis y utilización del espacio interior de la ciudad está condicionado no sólo por factores económicos y sociales, también por las imágenes o representaciones mentales que las personas se hacen de los lugares en los que viven o conocen a través de las fuentes de información que existen. Las imágenes mentales están determinadas por los caminos que utilizamos para desplazarnos, los lugares que frecuentamos y los sentimientos de identificación o rechazo con el espacio objeto de uso cotidiano. Para alcanzar ese conocimiento percibido se presentarán los resultados de encuestas y elaboración de mapas mentales llevados a cabo entre alumnos universitarios residentes en Valencia. A partir de ellos se avanzará en el conocimiento, realizándose, por parte de los distintos agentes que intervienen en la planificación del espacio, propues- 
tas de mejora que contribuyan al crecimiento armónico y sostenible, corrigiendo deficiencias palpables que puedan alterar la calidad de vida de los ciudadanos.

Palabras Clave: Valencia; geografía del comportamiento y de la percepción; imágenes mentales; urbanismo.

\begin{abstract}
The analysis and use of the interior space of the city, is conditioned not only by economic and social factors, also by images or mental representations that people make the places we live or know through sources of information world. Mental images are determined by the ways we use to get around, the places we frequent and feelings of rejection or identification with space everyday object. To achieve that perceived knowledge survey results and developing mental maps conducted among college students living in Valencia will be presented. From them will advance knowledge, it performed by the different actors involved in space planning improvement proposals that contribute to the harmonious and sustainable growth, palpable correcting deficiencies that may affect the quality of life of citizens.
\end{abstract}

KeY WORDS: Valencia; Behavioral Geography and Perception; mental images; town planning.

\title{
RÉSUMÉ
}

Lanalyse et l'utilisation de l'espace intérieur de la ville, est conditionnée non seulement par des facteurs économiques et sociaux, aussi par des images ou des représentations mentales que les gens font les endroits où nous vivons ou savent grâce à des sources d'information monde. Les images mentales sont déterminées par les moyens que nous utilisons pour se déplacer, les endroits que nous fréquentons et des sentiments de rejet ou d'identification avec l'objet espace de tous les jours. Pour atteindre cet perçu résultats de l'enquête de connaissances et le développement de cartes mentales menées chez les étudiants vivant à Valence sera présenté. De leur feront progresser le savoir, il effectué par les différents acteurs impliqués dans les propositions d'amélioration de la planification de l'espace qui contribuent à la croissance harmonieuse et durable, les carences de correction palpables qui peuvent affecter la qualité de vie des citoyens.

Mots CLÉs: Valence; Géographie et perception des comportements; images mentales; urbanisme. 


\section{ANEXO. CUESTIONARIO REALIZADO SOBRE LA PERCEPCIÓN URBANA DE} VALENCIA

Edad.

Profesión Sexo

$1^{\circ} \mathrm{Si}$ cierra los ojos y piensa en la ciudad de Valencia ¿Qué cinco imágenes particulares acuden a su mente? Enumérela de la primera imagen que le aparece a la última.

$1^{\mathrm{a}}$

$2^{\mathrm{a}}$

$3^{\mathrm{a}}$

$4^{\mathrm{a}}$

$5^{\mathrm{a}}$

$2^{\circ}$ Evalúe el grado de atracción de la ciudad de Valencia (señale con un $\mathrm{x}$ una de las propuestas)

\begin{tabular}{|l|l|}
\hline Nada atractiva & \\
\hline Poco atractiva & \\
\hline Atractiva & \\
\hline Muy atractiva & \\
\hline
\end{tabular}

$3^{\circ} \mathrm{Si}$ tuviera que dejar la ciudad en la que vive actualmente, se sentiría:

\begin{tabular}{|l|l|}
\hline Muy triste & \\
\hline Triste & \\
\hline Indiferente & \\
\hline Feliz & \\
\hline Muy feliz & \\
\hline
\end{tabular}

$4^{\circ}$ Si tuviese que cambiar de ciudad, ¿Qué cosas de la ciudad en la que vive cree echaría en falta? Enumérala de la primera idea que le aparece a la última

$1^{\mathrm{a}}$

$2^{\mathrm{a}}$

$3^{\mathrm{a}}$

$4^{\mathrm{a}}$

$5^{\mathrm{a}}$ 
$5^{\circ}$ Imagínese que le visita un amigo que llega por primera vez a Valencia. ¿Indique los cinco elementos que le indicaría visitase?

\begin{tabular}{l}
1 \\
$2 \square$ \\
4 \\
5 \\
\hline
\end{tabular}

$6^{\circ}$ Escriba cinco palabras que definan características de ventajas e inconvenientes del Centro urbano de Valencia:

\begin{tabular}{|c|c|}
\hline & 1 \\
\hline 2 & 2 \\
\hline 3 & 3 \\
\hline 4 & 4 \\
\hline 5 & 5 \\
\hline
\end{tabular}

$7^{\circ}$ ¿A qué suele ir al Centro? (Señala con una $x$ las tres más usadas)

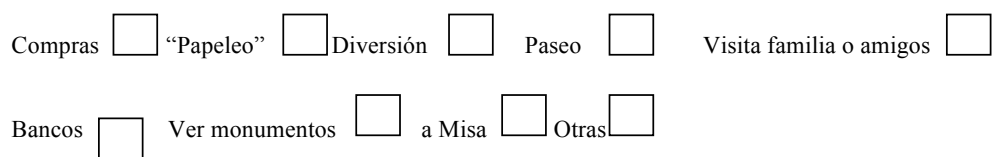

$8^{\circ}$ Medio de transporte más utilizado para desplazarse dentro de la ciudad: (Señala con una $x$ el más usado)

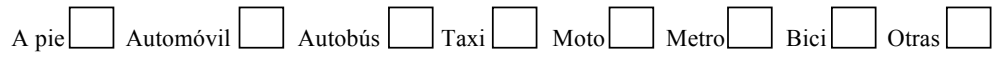

$9^{\circ}$ Haz una lista de los barrios de Valencia que más le gustaría para vivir, cítalos por orden de mayor a menor preferencia (cinco).

1

2

3

4

5

Estudios Geográficos, Vol. LXXVI, 278, pp. 203-33, enero-junio 2015

ISSN: 0014-1496, eISSN: 1988-8546, doi: 10.3989/estgeogr.201507 
$10^{\circ}$ Valore el grado de atracción turística de la ciudad de Valencia (Desde el $\mathrm{n}^{\circ} 0$ nada atractivo al $\mathrm{n}^{\circ} 5$ muy atractivo). Señale con un $\mathrm{x}$ la valoración de cada uno de ellos.

\begin{tabular}{|c|c|c|c|c|c|c|}
\hline Atractivo turístico & 0 & 1 & 2 & 3 & 4 & 5 \\
\hline Albufera & & & & & & \\
\hline Bioparc & & & & & & \\
\hline Casco Histórico y monumentos singulares (Ciutat Vella) & & & & & & \\
\hline Ciudad de las Ciencias y las Artes y Oceanográfico & & & & & & \\
\hline Clima mediterráneo & & & & & & \\
\hline Competiciones náuticas y puerto deportivo & & & & & & \\
\hline Compras y comercio & & & & & & \\
\hline Feria de Valencia & & & & & & \\
\hline Gastronomía & & & & & & \\
\hline Instalaciones, puentes y jardines próximos al cauce viejo & & & & & & \\
\hline Fallas & & & & & & \\
\hline Museos y eventos culturales & & & & & & \\
\hline Ocio en general & & & & & & \\
\hline Playas & & & & & & \\
\hline Grado de satisfacción que tiene como habitante de la ciudad & & & & & & \\
\hline
\end{tabular}

En caso de NO aparecer algún atractivo turístico más, lo puede indicar a continuación:

¡MUCHAS GRACIAS POR SU VALIOSA COLABORACIÓN; 